\title{
Utilization Pattern of Antiplatelet and Anticoagulant Medicines Among the Patients Suffering From Atrial Fibrillation
}

\author{
Sandip Jadav, Chandresh Dumatar
}

\section{Sandip Jadav, Chandresh Dumatar}

Department of Pharmacology, B. J. Medical College, Ahmedabad, Gujarat, India.

\section{Correspondence}

Dr. Sandip Jadav, Department of Pharmacology, B. J. Medical College, Ahmedabad, Gujarat, India- 380016. Email: sandip09jadu@gmail.com

\section{History}

- Submission Date: 03-09-15;

- Review completed: 18-06-16;

- Accepted Date: 22-06-16.

DOI : 10.5530/ijmedph.2016.2.10

Article Available online

http://www.ijmedph.org/v6/i2

\section{Copyright}

(C) 2016 Phcog.Net. This is an open-access article distributed under the terms of the Creative Commons Attribution 4.0 International license.

\begin{abstract}
Background: Antithrombotic therapy is recommended in atrial fibrillation (AF) patients due to high risk of stroke. However, antithrombotic therapy is often underutilized due to adverse effects and limited data available in Indian population.
\end{abstract}

Aims: Primary objective was to study usage pattern of antiplatelet and anticoagulant drugs in AF patients. Secondary objective was to assess the risk of stroke and compare usage pattern of antithrombotic drugs in non-valvular atrial fibrillation (NVAF) patients with application of CHADS2 and CHA2DS2-VASc score.

Materials and Methods: A prospective and observational study was conducted in outpatient department for period of one year in patients $>35$ years of either gender diagnosed with AF due to any established cause. CHADS2 and CHA2DS2-VASc score were used to assess risk of stroke among NVAF patients.

Results: 111 patients diagnosed with AF (mean age 54 years; 54.96\% female) were analyzed and out of these, 78 patients were valvular AF patients and 33 were NVAF patients. Anticoagulants were predominantly prescribed in 60 valvular AF patients. Out of 33 NVAF patients, 19 (57.57\%) patients had CHADS2 score 1 while as per CHA2DS2-VASc score 28 $(84.84 \%)$ patients had score $\geq 2$. Out of 33 NVAF patients, $15(45.45 \%)$ patients were prescribed warfarin, aspirin in $12(36.36 \%)$ patients and no antithrombotic therapy in $6(18.18 \%)$ patients.

Conclusion: Oral anticoagulant drugs are most commonly prescribed antithrombotic drugs in valvular AF and NVAF patients for stroke prevention. CHADS2 and CHA2DS2-VASc score are easy, simple schemes to assess stroke risk in NVAF patients and helps physicians and patients to choose most suitable antithrombotic therapy.

Key words: Atrial fibrillation, Anticoagulant, Antiplatelet, $\mathrm{CHADS}_{2}, \mathrm{CHA}_{2} \mathrm{DS}_{2}-\mathrm{VASc}$ score.

\section{INTRODUCTION}

Atrial fibrillation is the most common sustained cardiac arrhythmia responsible for major health problem associated with increased morbidity and by $\mathrm{AF}$ and its' prevalence increases with age from $0.5 \%$ at $40-50$ years to $5-15 \%$ at 80 years. ${ }^{2,3}$ The prevalence of $\mathrm{AF}$ is $0.1 \%-2.8 \%$ in East, $0.8 \%-2.8 \%$ in China and $0.1 \%$ in India. ${ }^{4}$ There is a five times higher risk of stroke in AF patients compared to those in sinus rhythm and accounts for almost $10-15 \%$ of all ischaemic strokes. ${ }^{5}$ Strokes secondary to AF are more severe and cause greater disability compared secondary to atherosclerotic disease which results in significant costs related to hospitalizations and chronic disability. ${ }^{5,6}$ Different modalities aimed at reducing embolic events includes therapy with aspirin, combination of aspirin and clopidogrel, and warfarin or one of the new oral anticoagulants targeting either thrombin or Factor Xa. ${ }^{6}$ Non-valvular AF (NVAF) is defined as patients with AF in the absence mortality. ${ }^{1}$ Around $1-2 \%$ of the population is affected of rheumatic mitral valve disease, a prosthetic heart valve, or mitral valve repair. ${ }^{7}$

AF patients not treated with antithrombotic therapy show increased incidence of stroke, average $4 \%-5 \%$ per year. ${ }^{8}$ In NVAF patients, risk of stroke depends on the presence of prior cerebral ischaemia, comorbid conditions and use of antithrombotic therapy, but without antithrombotic therapy, the rate varies from 2-10 strokes per 100 patient years. ${ }^{9}$

ESC (European Society of Cardiology) and AHA (American Heart Association) guidelines are used to prevent stroke in NVAF patients particularly in Western countries. Several risk stratification schemes have been developed and utilized to predict thromboembolism risk in NVAF patients in developed countries. The aim of stroke prediction schemes is to help clinicians and patients to select the most appropriate antithrombotic therapy for stroke prevention. ${ }^{10} \mathrm{CHADS} 2$ is an acronym for 'major' risk factors (congestive heart failure, hypertension, age, diabetes and history of a previous stroke or transient ischemic attack). CHA2DS2-VASc score has been
Cite this article : Jadav S, Dumatar C. Utilization Pattern of Antiplatelet and Anticoagulant Medicines Among the Patients Suffering From Atrial Fibrillation. J. Med. Public Health, 2016; 6(2):103-108. 
proposed with inclusion of 'non major' stroke risk factors (i.e. vascular disease, age 65-74 years and female gender). ${ }^{1,11}$ CHADS2 score is a clinical prediction rule for estimating the risk of stroke in patients with NVAF which is commonly associated with thromboembolic stroke. It is simple and has been validated by number of studies. ${ }^{9}$ Long term warfarin treatment reduces stroke rate in untreated rheumatic heart disease (RHD) from $5 \%$ to $0.7-0.8 \%$ with targeted INR (International normalized ratio) 2.0-3.0. If embolization occurs, low dose aspirin (75-100 mg per day) is added with targeted INR 2.5-3.5. ${ }^{12}$ However, in clinical practice warfarin therapy is underused because of its narrow therapeutic range and major complications. ${ }^{13-15}$ Aspirin seems to be efficacious mainly in the prevention of smaller and non cardioembolic strokes. ${ }^{16}$ Different modalities aimed at reducing embolic events includes therapy with aspirin, combination of aspirin and clopidogrel, and warfarin or one of the new oral anticoagulants targeting either thrombin or Factor Xa. ${ }^{6}$

Data regarding usage of antiplatelet and anticoagulant drugs in AF patients is scarce and well established guidelines are not available in India. Hence, the present study was conducted to evaluate the usage pattern of antithrombotic therapy for prevention of stroke in AF patients in India. It was thought worthwhile to assess risk of stroke using CHADS2 and CHA2DS2-VASc score in NVAF patients.

\section{MATERIALS AND METHODS}

It was an observational, prospective and single centre study carried out for one year (November 2011 to October 2012) in two units of outpatient department of Medicine, Civil Hospital. Prior permission obtained from respective Head of Unit and protocol was approved by Institutional Ethics Committee of Civil Hospital (Ref no. EC/ Approval/2/77/18.4.2012).

Patients $>35$ years of either gender diagnosed with AF due to any established cause and willing to participate in the study were included while patients diagnosed AF due to surgery and / or trauma to heart, drugs (e.g. digitalis, alcohol, thyroxine, amphetamine, and adrenaline) were excluded.

Informed consent was obtained from each patient and enrolled patient was followed monthly for period of 4 months. Detail history, clinical and laboratory examination, and antithrombotic drugs prescribed for each patient were recorded in a pre-tested case record form. Laboratory investigations, prothrombin time and INR monitoring were recorded on monthly basis. All AF patients who met exclusion criteria were analyzed for prescription pattern of anti platelet and anticoagulant drugs. CHADS2 and CHA2DS2-VASc score recommended by ESC and AHA were used to assess risk of stroke in NVAF patient's only. ${ }^{7}$ and correlation of usage pattern of anticoagulant and anti platelet drugs with their scoring was done.

\section{Statistical analysis}

The data collected was compiled, entered and analyzed in Microsoft Excel spreadsheet (version 2007). GraphPad Prism (demo version 6) software was used to calculate descriptive statistics. Frequencies and percentages were used to describe categorical variables while mean and standard deviation were used to summarize continuous variables.

\section{RESULTS}

\section{Baseline characteristics}

Total 111 AF patients were enrolled in the study. Male: Female ratio was $0.81: 1$ and mean age of the patients was $54.19 \pm 9.24$ years with range from 36-85 years. Details of general characteristics of AF patients are shown in Table 1. RHD was cause of AF in 78 (70.27\%) patients, while in $33(29.72 \%)$ NVAF patients, cause of AF were like hypertension $(\mathrm{n}=11)$,
Table 1: General characteristics of AF patients $(n=111)$

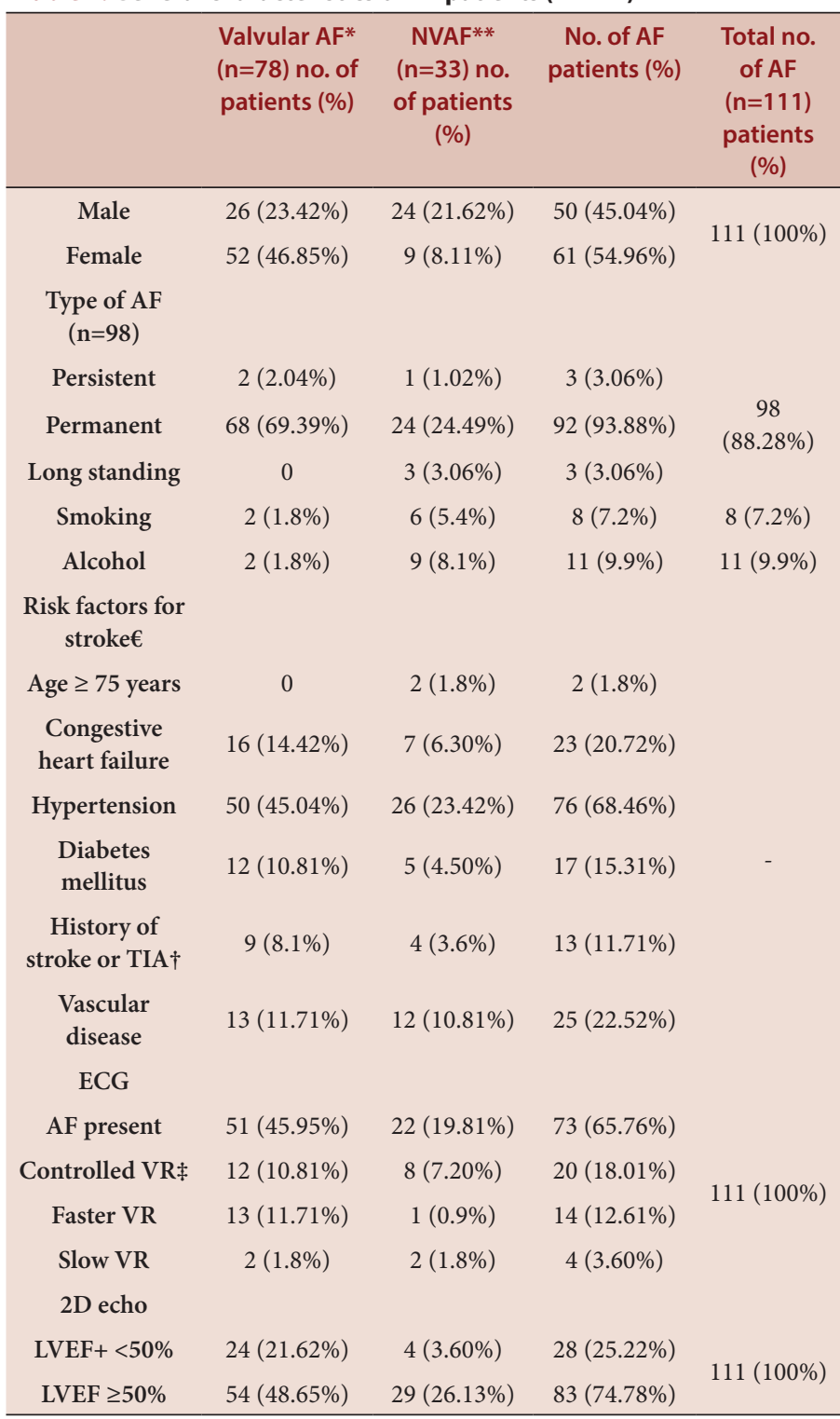

* AF: atrial fibrillation, $\dagger$ TIA: Transient ischemic attack, $\ddagger$ VR: Ventricular rate, +LVEF: Left ventricular ejection fraction, ${ }^{* *}$ NVAF: non valvular atrial fibrillation, ${ }^{€}$ Data shown as percentage in risk factors for valvular $\operatorname{AF}(n=78)$ and NVAF patients $(n=33)$; multiple risk factors present in these patients.

ischemic heart disease $(n=14)$, congestive heart failure $(n=7)$ and hyperthyroidism $(\mathrm{n}=1)$.

\section{Utilization pattern}

Out of 111 AF patients, 17 (15.31\%) patients were not prescribed any antithrombotic drug. In remaining $94(84.68 \%)$ patients details of antithrombotic drugs prescribed are shown in Table 2.

All 94 AF patients received only one antithrombotic agent in form of either anticoagulant or antiplatelet. Out of these 94 antithrombotic drugs prescribed, $73(77.65 \%)$ drugs were prescribed by brand name while 21 (22.34\%) drugs by generic name and $34(36.18 \%)$ drugs were supplied by the hospital drug store, while 60 (63.82\%) drugs were supplied from private medical store. Only warfarin and aspirin were included in Essential Medicines List of India and Gujarat, 2011..$^{17,18}$ 
Table 2: Utilization pattern of anticoagulant and antiplatelet medications in AF patients $(n=111)$

\begin{tabular}{ccccc}
\hline Group of drug & Drug & $\begin{array}{c}\text { Dose/ } \\
\text { day }\end{array}$ & $\begin{array}{c}\text { No. of AF } \\
\text { patients }\end{array}$ & $\begin{array}{c}\text { Total no. } \\
\text { of AF patients }\end{array}$ \\
\hline \multirow{2}{*}{ Anticoagulant } & Warfarin & $2 \mathrm{mg}$ & 6 & \\
& Acenocoumarol & $1 \mathrm{mg}$ & 51 & 60 \\
\multirow{4}{*}{ Antiplatelet } & & $75 \mathrm{mg}$ & 12 & \\
& Aspirin & $125 \mathrm{mg}$ & $4^{*}$ & 34 \\
No antithrombotic & & $325 \mathrm{mg}$ & $18^{*}$ & \\
\hline
\end{tabular}

${ }^{*}$ One patient was prescribed 1 tablet of $125 \mathrm{mg}$ daily, ${ }^{*}$ one patient was prescribed 1 tablet of $325 \mathrm{mg}$ tablet daily.

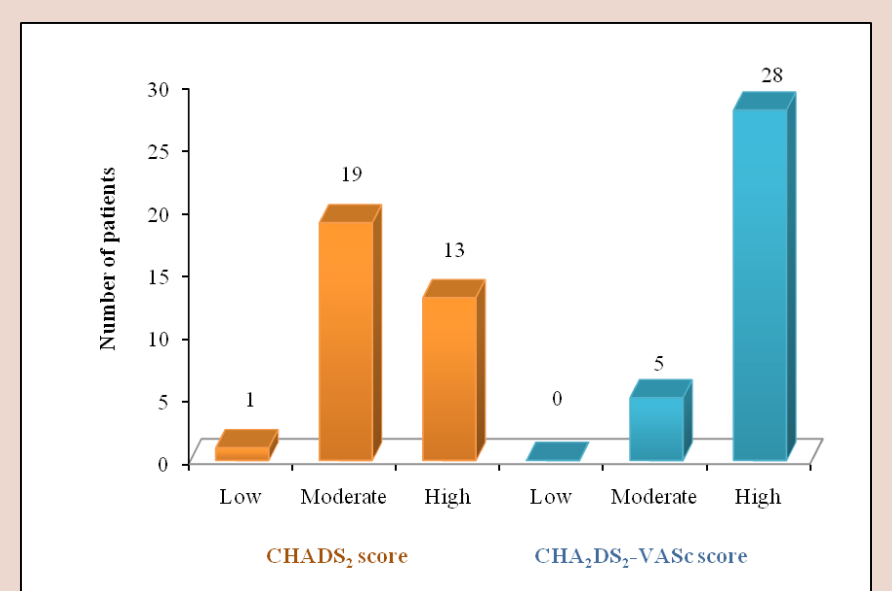

Figure 1: Stratification of stroke risk based on CHADS2 and CHA2DS2VASc score in NVAF patients $(n=33)$

\section{Stratifi cation of NVAF patients as per CHADS2 and CHA2DS2-VASc score}

Out of 111 AF patients, 33 (29.72\%) patients were NVAF patients. As per CHADS2 score maximum numbers of patients were in 'moderate' risk while as per CHA2DS2-VASc score maximum numbers of patients were in 'high' risk (Figure 1). Comparison between these two scores showed that number of patients at 'high' risk of stroke increased (from 39.40\% to $84.84 \%$ ) while patients at 'moderate' risk of stroke decreased (from $57.57 \%$ to $15.16 \%$ ) after association of CHADS2 score to CHA2DS2VASc score (Figure 1).

Out of 33 NVAF patients, 15 (45.45\%) patients were prescribed warfarin, $12(36.36 \%)$ were prescribed aspirin and $6(18.18 \%)$ patients were not prescribed any antithrombotic. Details of antithrombotic therapy as per stroke risk category are given in Figure 2.

\section{Monitoring and outcome:}

No modification in the treatment of either antiplatelet or anticoagulant drug was observed in any AF patient during the study period. Among $60(76.92 \%)$ valvular AF patients prescribed anticoagulant [warfarin $(\mathrm{n}=57)$ and acenocoumarol $(\mathrm{n}=3)]$, mean INR value was $2.13 \pm 0.17$ with range from 1.79 to 2.5. Among 15 (45.45\%) NVAF patients prescribed only warfarin, mean INR value was $1.92 \pm 0.07$ with range from 1.79 to 2.04 (Figure 3 ).

None of these AF patients developed stroke, systemic embolism or death during follow up. Also major bleeding events and hospitalization were not found in any AF patient during follow up.

\section{DISCUSSION}

In this study we investigated antithrombotic prescribing pattern in AF patients with rheumatic (valvular) and non-valvular AF in a tertiary care setting. Out of $111 \mathrm{AF}$ enrolled patient majority of the patients were valvular AF patients $(\mathrm{n}=78)$ while $33(29.72 \%)$ patients were NVAF patients. Most commonly prescribed antithrombotic for prevention of stroke in AF patients was anticoagulant $(n=60)$. Most commonly pre-

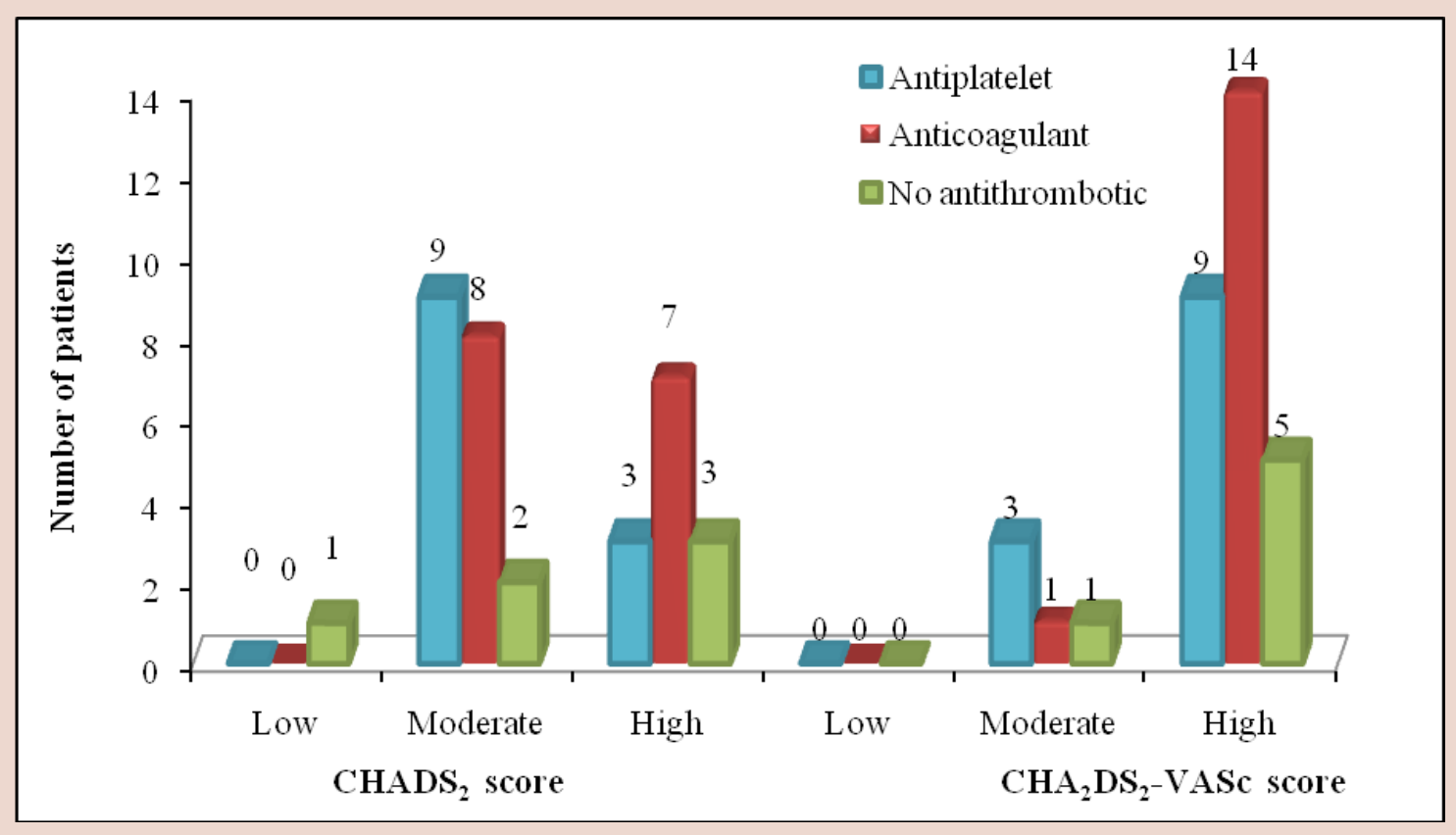

Figure 2: Antithrombotic treatment based on CHADS2 and CHA2DS2-VASc score in NVAF patients $(n=33)$ 


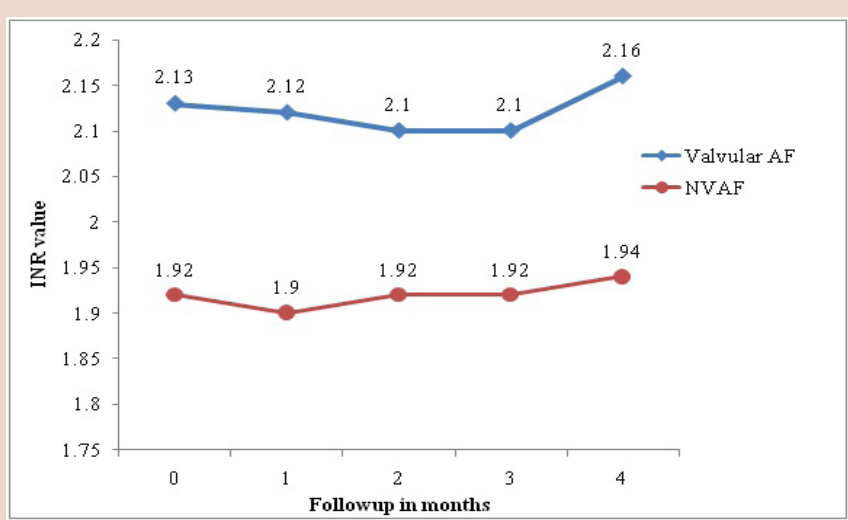

Figure 3: Mean INR value changes in valvular AF $(n=60)$ and NVAF $(n=15)$ patients received anticoagualnt during study

scribed anticoagulant in AF patients was warfarin $(n=57)$ and antiplatelet drug was aspirin $(n=34)$. We observed a larger number of female AF patients (54.96\%) in our study. This is consistent with another study conducted in India which showed that $58 \%$ were female and $42 \%$ male. $^{19}$ Reason could be that RHD was more common in females..$^{20}$ In contradiction to this, in other studies a large number of males were observed to take the antithrombotic therapy as compared to females. ${ }^{20-22}$

Our study included the patients of varying ages (36 to 85 years) with mean age $54.19 \pm 9.24$ years. However, in other studies mean age was $60-80$ years. ${ }^{23-25}$ In present study, maximum number of patients $(\mathrm{n}=40)$ belonged to $46-55$ years of age group. However, other study showed that most of the patients belonged to the age group of 41-60 years and with mean age of 47 years. ${ }^{26}$ Age distribution is consistent with other Indian studies but differs from western studies which may be due to low prevalence of RHD in western countries. ${ }^{27}$

In present study, RHD was observed in $70.27 \%$ in AF patients and hypertension in $23.42 \%$ NVAF patients. Yet another study showed $78 \%$ patients had AF due to RHD, while IHD was present in $11 \%$ patients. ${ }^{19}$ It is consistent with another study which showed that AF due to RHD was observed in $31.1 \%$ patients in India compared to $2.2 \%$ in North America, $2-3.7 \%$ in Europe, $15.3 \%$ in China. ${ }^{28}$

Anticoagulants were predominantly prescribed (54.05\% patients) in our study. This was similar to one study conducted in United States where $67 \%$ patients were prescribed anticoagulant. ${ }^{21}$ However, two other studies showed that the extent of use of anticoagulant was $76-79 \%{ }^{29,30}$ Anti platelets prescribed in $30.63 \%$ patients in our study was similar to study in United States where $45.9 \%$ patients were prescribed antiplatelets. ${ }^{31}$ However, one study in China showed that $73.4 \%$ patients were prescribed antiplatelets. ${ }^{32}$ This shows that use of antiplatelet and anticoagulant drugs in AF patients is highly variable. Many eligible patients were not receiving adequate warfarin therapy. Reason could be delayed onset of action (4-5 days), dose of warfarin varies from patient to patient (need for trial and error), need for frequent INR monitoring (every $2-4$ weeks) and narrow therapeutic range of INR (2.0-3.0). Newer oral anticoagulants (NOACs) have some limitations like no antidote, unknown long term safety and lack of validated tests to monitor anticoagulant effect. ${ }^{33} \mathrm{In}$ comparison to NOACs, for warfarin anticoagulant monitoring is validated, antidote is available for toxicity and long term safety is well established. Easy availability in a hospital pharmacy may also affect the usage pattern of a particular drug. We have further noted that acenocoumarol was used in three patients in our study.
In present study, 17 (15.31\%) AF patients out of total $111 \mathrm{AF}$ patients were not prescribed antithrombotic therapy. Similar finding was noted in another study where among 150 known AF patients, 54 (36\%) patients were not on any antithrombotic treatment. ${ }^{34}$ Reason for not prescribing antithrombotic drugs was not available among these AF patients. It could be due to contraindications, development of toxicity or temporary withdrawal of antithrombotic medications. However, in another study $39(11 \%)$ patients had major contraindications to anticoagulation and 66 (19\%) patients had minor contraindications. ${ }^{35}$

We have observed in this study that only 3 different antithrombotic were used. The reasons for this may be poor availability and higher cost of NOACs. We observed that antiplatelet and anticoagulant were used exclusively by oral routes. Reason could be that antithrombotic drugs were not available in different formulations in India. Also parenteral therapy requires hospitalization which increases cost and monitoring of patients in chronic conditions like AF. Also currently not all parenteral antiplatelet and anticoagulant are approved for prophylaxis in AF patients.

We have observed that all AF patients (51.35\%) treated with warfarin were found to be adherent to treatment schedule at end of study period. However, another study showed that $67 \%$ patients were treated with warfarin and it was discontinued within 1 year in $25.4 \%$ patients, interrupted in $32.6 \%$ patients and $45.7 \%$ patients remained on warfarin at the end of follow up. ${ }^{23}$ However, in our study follow up period was short (4 months) compared to another study where follow up period was longer (2 years). ${ }^{36}$

In present study out of 33 NVAF patients, $45.45 \%$ patients were prescribed warfarin, $36.36 \%$ were prescribed aspirin and no antithrombotic therapy in $18.19 \%$ patients. In accordance to this; a study conducted among 207 patients in Hong Kong showed that $44 \%$ NVAF patients were receiving warfarin, $34.1 \%$ aspirin and $22 \%$ no antithrombotic therapy. ${ }^{37}$ We were not able to observe contraindications for warfarin in AF patients in our study. However, another study showed that among 429 patients, the most common contraindications for warfarin were bleeding history (27\%), frequent falls (27\%) and dementia (58\%). ${ }^{38}$

In present study out of 33 NVAF patients, 15 patients were prescribed warfarin and mean INR value was $1.92 \pm 0.07$ and range of INR was 1.89-2.0. In another study out of 620 patients, majority of patients $(63.2 \% ; \mathrm{n}=392)$ were not within the target therapeutic range for $\mathrm{AF}^{36}$ Moreover, this may explain the difficulty of managing patients on anticoagulant treatment. It is important to monitor anticoagulation status but it is not possible for all patients due to higher cost, need for frequent monitoring and dose adjustments.

In NVAF patients, we have observed CHADS2 score was $\geq 2$ in $39.40 \%$ and CHA2DS2-VASc score $\geq 2$ in $84.84 \%$ patients. In accordance to this, another study showed that $56.9 \%$ patients had a CHADS2 score $\geq 2$ and $84.5 \%$ had a CHA2DS2-VASc score $\geq 2 .{ }^{39}$ We observed that in 13 patients with CHADS2 score of $\geq 2$, warfarin was prescribed in $53.84 \%$ patients. Another study showed that among 5612 patients with a CHADS2 score of $\geq 2,55.0 \%$ patients were treated with warfarin..$^{40}$ In our study, prescription of oral anticoagulants among 'high' risk groups was 53.84\% and 50\% as per CHADS2 and CHA2DS2-VASc score respectively. In accordance to this, another study showed only $53.0 \%$ and $50.7 \%$ of 'high' risk groups were using oral anticoagulants as per CHADS2 and CHA2DS2-VASc score respectively, with the majority of the remaining receiving an antiplatelet agent. $^{39}$

In our study as per CHA2DS2-VASc score we observed that no patient was at low risk, $15.15 \%$ patients were at moderate risk and $84.84 \%$ were at high risk. In another study, $4.3 \%$ patients were at low risk of stroke, $9.7 \%$ were at moderate risk, and $86 \%$ were at high risk. ${ }^{36}$ In present study $50 \%$ patients were prescribed anticoagulants; $84.84 \%$ patients had score 
CHA2DS2-VASc score $\geq 2$. While $32.14 \%$ patients were prescribed antiplatelets; $15.16 \%$ patients had CHA2DS2-VASc score 1 and no patient was at low risk. However, another study observed that $84 \%$ patients were prescribed anticoagulants, $91 \%$ had a CHA2DS2-VASc score $\geq 2,7.3 \%$ were at moderate risk and $1.7 \%$ patients were at low risk; similar rates were observed for antiplatelet drugs. ${ }^{36}$

In our study as per CHADS2 score, $39.40 \%$ of NVAF patients were at high risk but, when stratified by CHA2DS2-VASc score, the proportion of patients at high risk of stroke increased up to $84.84 \%$. Similar finding was seen in another study where CHADS2 score showed that $20 \%$ of NVAF patients were at high risk but as per CHA2DS2-VASc score, it increased up to $86 \%{ }^{36}$

There is lack of data about utilization of anticoagulant and antiplatelet drugs in India particularly after introduction of newer antithrombotic drugs e.g. dabigatran and acenocoumarol. As follow up period was short we were not able to determine any change in drug therapy from anticoagulant to antiplatelet and vice versa. Since the study duration was only one year, we were not able to determine effectiveness of antithrombotic therapy in prevention of stroke. Our study was performed at Government hospital where essential drugs are available free of cost and this itself may have excluded us to document the use of newer and expensive drugs. Risk factors based such scores like CHADS2 can be implemented in Indian population with modifications like age $\geq 65$ years but with further research. Prevention of stroke in AF patients especially in Indian setup (limited resources, lack and high cost of laboratory investigations, non availability of newer drugs) should be outlined in a rational manner.

\section{CONCLUSION}

Warfarin and aspirin are most commonly prescribed antithrombotic medications for prevention of stroke in AF patients. Stroke risk stratification scoring system such as CHADS2 is easy, simple to use and helps physicians and patients to choose most suitable antithrombotic therapy. Hence, further research on NOACs and identification of patient at risk and education on stroke prevention is still required in countries like India.

\section{ACKNOWLEDGEMENT}

None.

\section{CONFLICT OF INTEREST}

None.

\section{SOURCE(S) OF SUPPORT}

None.

\section{LIST OF ABBREVIATIONS}

AF: Atrial fibrillation; NVAF: Non valvular atrial fibrillation; ESC: European society of cardiology; AHA: American Heart Association; INR: International normalized ratio; RHD: Rheumatic heart disease; NOACs: Newer oral anticoagulants.

\section{REFERENCES}

1. Sanoski CA, Schoen MD, Bauman JL. The Arrhythmias. In: Dipiro JT, Talbert RL, Yee GC, Matzke GR, Wells BG, Posey LM, editors. Pharmacotherapy: A Pathophysiological approach. New York: Mc-Graw Hill; 2011;00-113.

2. Naccarelli GV, Varker $H$, Lin J, Schulman KL. Increasing prevalence of atrial fibrillation and flutter in the United States. Am J Cardiol. 2009;104(11):1534-9.

3. Pepine CJ. Effects of pharmacologic therapy on health-related quality of life in elderly patients with atrial fibrillation: A systematic review of randomized and nonrandomized trials. Clin Med Insights Cardiol. 2013,7:1-20.

4. Guo Y, Lip GY, Apostolakis S. The unmet need of stroke prevention in atrial fibrillation in the Far East and South East Asia. Malays J Med Sci. 2012,19(3):1-7.

5. Danielle ES, Christian BX, Helen MP, Lip YH, Deirdre AL. Educational intervention on patients' knowledge of atrial fibrillation and anticoagulant therapy, INR control, and outcome of treatment with warfarin (TREAT). BMC Cardiovasc Disord. 2010,10:21.

6. Yaariv K, Yana S. Current issues in atrial fibrillation. ISRN Cardiology. 2012;10:376071

7. Fuster V, Rydén LE, Cannom DS, Crijns HJ, Curtis AB, Ellenbogen KA, et al. American College of Cardiology/American Heart Association Task Force on Practice Guidelines; European Society of Cardiology Committee for Practice Guidelines; European Heart Rhythm Association; Heart Rhythm Society: ACC/ AHA/ESC 2006 guidelines for the management of patients with atrial fibrillation: A report of the American College of Cardiology/American Heart Association task force on practice guidelines and the European society of cardiology committee for practice guidelines (writing committee to revise the 2001 guidelines for the management of patients with atrial fibrillation): developed in collaboration with the European heart rhythm association and the heart rhythm society. Circulation. 2006;114(7):e257-354.

8. Abcede HG, Ovbiagele B. Update on antithrombotic therapy for stroke prevention in atrial fibrillation. Curr Treat Options Cardio vasc Med. 2010;12(3):250-60.

9. Gage BF, van Walraven C, Peace L, Hart RG, Koudstaal PJ, Boode BS, et al. Selecting patients with atrial fibrillation for anticoagulation: stroke risk stratification in patients taking aspirin. Circulation. 2004;110(116):2287-92.

10. Karthikeyan G, Eikelboom JW. The CHADS2 score for stroke risk stratification in atrial fibrillation -friend or foe? Thromb Haemost. 2010;104(1):45-8.

11. Camm AJ, Kirchhof P, Lip GY, Schotten U, Savelieva I, Ernst S, Van Gelder IC, et al. European Heart Rhythm Association; European Association for CardioThoracic Surgery: Guidelines for the management of atrial fibrillation: The task force for the management of atrial fibrillation of the European Society of Cardiology (ESC). Eur Heart J. 2010;31(19): 2369-429.

12. World Health Organization. Rheumatic fever and rheumatic heart disease Report of aWHO expert consultation. [updated 2014 Jun 6 cited 2013 Dec 5]. Available from: http://www.who.int/cardiovascular_diseases/publications/trs923/en/

13. Majeed A, Moser K, Carroll K. Trends in the prevalence and management of atrial fibrillation in general practice in England and Wales, 1994-1998: Analysis of data from the general practice research database. Heart. 2001;86(3):284-8.

14. Fang MC, Stafford RS, Ruskin JN, Singer DE. National trends in antiarrhythmic and antithrombotic medication use in atrial fibrillation. Arch Intern Med. 2004;164(1):55-60.

15. Dewilde S, Carey IM, Emmas C, Richards N, Cook DG. Trends in the prevalence of diagnosed atrial fibrillation, its treatment with anticoagulation and predictors of such treatment in UK primary care. Heart. 2006;92(8):1064-70.

16. Ferro D, Loffredo L, Polimeni L, Violi F. Underuse of oral anticoagulants in patients with nonvalvular atrial fibrillation in Italy. Intern Emerg Med. 2007;2(1):24-8.

17. National list of Essential Medicines Government of India, Ministry of Health and Family Welfare, Directorate General of Health Services. New Delhi, 2012 [updated 2013 Apr 12 cited 2013 Oct 25]. Available from: http://cdsco.nic.in/ National\%20List\%20of\%20Essential\%20Medicine-\%20final\%20copy.pdf

18. Essential Medicines list of Gujarat. Central Medical Stores Organization, Gandhinagar, Gujarat, 2010. [updated 2014 Jun 6 cited 2013 Oct 25]. Available from: http://gujhealth.gov.in/images/essentiallistform2010-11.pdf

19. Patel DS, Chavda AB, Goswami BI. Clinical study \& etiological evaluation of atrial fibrillation at tertiary care hospital, Jamnagar, Gujarat, India. (A study of 100 cases). IJSR. 2012;1(4)

20. Bhardwaj R, Kandoria A, Marwah R, Vaidya P, Singh B, Dhiman P, et al. Prevalence of rheumatic fever and rheumatic heart disease in rural population of Himachal-A population based study. J Assoc Physicians India. 2012;60(5):13-14

21. Ewen E, Zhang Z, Simon TA, Kolm P, Liu X, Weintraub WS. Patterns of warfarin use and subsequent outcomes in atrial fibrillation in primary care practices. Vasc Health Risk Manag. 2012;8:587-98.

22. Desai HV, Aronow WS, Gandhi K, Bakerywala S, Laimuanpuii J, Sharma M et al. Association of warfarin use with CHADS2 score in 441 patients with nonvalvular atrial fibrillation and no contraindications to warfarin. Prev Cardiol. 2010;13(4):172-74.

23. Mohammed MA, Marshall T, Nirantharakumar K, Stevens A, Fitzmaurice D. Patterns of warfarin use in subgroups of patients with atrial fibrillation: A cross sectional analysis of 430 general practices in the United Kingdom. PLOS ONE. 2013;8(5):e61979.

24. Shin HW, Kim YN, Bae HJ, Lee HM, Cho HO, ChoYK, et al. KORAF Investigator: Trends in oral anticoagulation therapy among Korean patients with atrial fibrillation: The Korean atrial fibrillation investigation. Korean Circ J. 2012;42(2):113-17.

25. Suarez J, Piccini JP, Liang L, Atherton JJ, Hayward CS, Krum H, et al. International variation in use of oral anticoagulation among heart failure patients with atrial fibrillation. Am Heart J. 2012;163(5):804-11. 
26. Nand V, Gupta AK, Mahmood SE, Kulshrestha M, Patiyal RK. Etiological profile and clinical presentation of patients with atrial fibrillation from a rural area of Bihar. NJMR. 2012; 2(2):124-7.

27. Markides $V$, Schilling RJ. Atrial fibrillation: Classification, pathophysiology, mechanism and drug treatment. Heart. 2003;89(8):939-43.

28. Global variation in the etiology and management of atrial fibrillation: results from a global atrial fibrillation registry. [updated 2013 Jun 8 cited 2013 Dec 4]. Available from: http://www.escardio.org/congresses/esc-2011/congressreports/Pages/711-6-AF-registry-global.aspx\#.UrSAweKMO_s

29. Ceresne L, Upshur RE. Atrial fibrillation in a primary care practice: prevalence and management. BMC Fam Pract. 2002;3(1):11.

30. Smoyer-Tomic K, Siu K, Walker DR, Johnson BH, Smith DM, Sander S, et al. Anticoagulant use, the prevalence of bridging, and relation to length of stay among hospitalized patients with non-valvular atrial fibrillation. Am J Cardiovasc Drugs. 2012,12(6):403-13.

31. Niska R, Han B. Anticoagulation for patients with atrial fibrillation in ambulatory care settings. J Am Board Fam Med. 2009;22(3):299-306.

32. Han W, Shen DT, Wang YM. Comparative study of warfarin and aspirin for stroke prevention in elderly patients with atrial fibrillation. Nan Fang Yi Ke Da Xue Xue Bao. 2006;26(6):851-55.

33. Ahmad Y, Lip GY. Stroke prevention in atrial fibrillation: concepts and controver- sies. Current Cardiology Reviews. 2012;8(4):290-301.

34. Burgess $C$, Ingham T, Woodbridge $M$, Weatherall M, Nowitz M. The use of antithrombotics in patients presenting with stroke and atrial fibrillation. Ther Clin Risk Manag. 2007;3(3):491-98.

35. Perez I, Melbourn A, Kalra L. Use of antithrombotic measures for stroke prevention in atrial fibrillation. Heart. 1999;82(5):570-74

36. Piccinocchi G, Laringe M, Guillaro B, Arpino G, Piccinocchi R, Nigro G, et al. Diagnosis and management of atrial fibrillation by primary care physicians in Italy a retrospective, observational analysis. Clin Drug Investig. 2012;32(11):771-77.

37. Leung CS, Tam KM. Antithrombotic treatment of atrial fibrillation in a regional hospital in Hong Kong. Hong Kong Med J. 2003;9(3):179-85.

38. McCormick D, Gurwitz JH, Goldberg RJ, Becker R, Tate JP, Elwell A, et al. Prevalence and quality of warfarin use for patients with atrial fibrillation in the longterm care setting. Arch Intern Med. 2001;161(20):2458-63.

39. Holt TA, Hunter TD, Gunnarsson C, Khan N, Cload P, Lip GY. Risk of stroke and oral anticoagulant use in atrial fibrillation: A cross-sectional survey. $\mathrm{Br} \mathrm{J}$ Gen Pract. 2012;62(603), e710-e7.

40. Chan PS, Maddox TM, Tang F, Spinler S, Spertus JA. Practice-level variation in warfarin use among outpatients with atrial fibrillation (From the NCDR PINNACLE program). Am J Cardiol. 2011;108(8):1136-40.

Cite this article : Jadav S, Dumatar C. Utilization Pattern of Antiplatelet and Anticoagulant Medicines Among the Patients Suffering From Atrial Fibrillation. J. Med. Public Health, 2016; 6(2):103-108. 